\title{
miR-203-3p participates in the suppression of diabetes-associated osteogenesis in the jaw bone through targeting Smad1
}

\author{
YUYING TANG ${ }^{1-3}$, LEILEI ZHENG ${ }^{2-4}$, JIE ZHOU $^{2-4}$, YANG CHEN $^{2-4}$, \\ LAN YANG ${ }^{2-4}$, FENG DENG ${ }^{2-4}$ and YUN HU ${ }^{2,3,5}$ \\ ${ }^{1}$ Department of Endodontics, The Affiliated Stomatology Hospital; ${ }^{2}$ Chongqing Key Laboratory of \\ Oral Diseases and Biomedical Sciences; ${ }^{3}$ Chongqing Municipal Key Laboratory of Oral Biomedical Engineering of \\ Higher Education; Departments of ${ }^{4}$ Orthodontics and ${ }^{5}$ Pediatric Dentistry, The Affiliated Stomatology Hospital, \\ Chongqing Medical University, Chongqing 401147, P.R. China
}

Received April 18, 2017; Accepted January 4, 2018

DOI: $10.3892 / \mathrm{ijmm} .2018 .3373$

\begin{abstract}
Certain microRNAs (miRs) have important roles in the maintenance of bone development and metabolism, and a variety of miRs are known to be deregulated in diabetes. The present study investigated the role of miR-203-3p in the regulation of bone loss by assessing jaw bones of a rat model of type 2 diabetes. The results indicated that miR-203-3p inhibited osteogenesis in the jaws of diabetic rats and in rat bone marrow mesenchymal stem cells cultured in high-glucose medium. A luciferase reporter assay was used to verify the bioinformatics prediction that miR-203-3p targets the 3'-untranslated region of Smad1, which is an important mediator of the bone morphogenetic protein (BMP)/Smad pathway. Overexpression of Smad1 attenuated the miR-203-3p-mediated suppression of osteogenic differentiation. It was therefore indicated that the BMP/Smad pathway is attenuated and the transforming growth factor- $\beta$ /activin pathway is promoted by Smad1 reduction. Taken together, it was indicated that miR-203-3p inhibits osteogenesis in jaw bones of diabetic rats by targeting Smad1 to inhibit the BMP/Smad pathway.
\end{abstract}

\section{Introduction}

Type 2 diabetes mellitus (T2DM) is one of the most prevalent metabolic diseases, which is characterized by high levels of blood glucose as a result of insulin resistance and relative insulin deficiency. Diabetes is often associated with impaired bone metabolism and calcium and phosphorus metabolism disorders, causing secondary osteopenia, osteoporosis and other diabetic bone diseases. Diabetes interferes with bone

Correspondence to: Dr Yun Hu, Department of Pediatric Dentistry, The Affiliated Stomatology Hospital, Chongqing Medical University, 426 Songshibei Road, Chongqing 401147, P.R. China E-mail: huyun197907@163.com

Key words: diabetes, miRNA-203-3p, osteogenesis, Smad1, jaw bone formation, increases the risk of fractures and impedes fracture healing. Jaw bones of DM patients often display loss of alveolar bone and osteoporosis, resulting in tooth loosening or even loss $(1,2)$. Dental implantation is an important method for the repair of missing teeth. However, diabetes-induced skeletal complications and an abnormal metabolic environment cause pathological changes that greatly reduce the success rate of dental implantation (3).

Unlike skeletal limbs, which originate from the mesoderm, the jaw develops from the neural crest of the embryo. Jaw injury is repaired by bone marrow mesenchymal stem cells (BMSCs) of neural crest origin, while limb bone injuries are repaired by mesoderm-derived BMSCs. Studies that examined the BMSCs of the jaw and the BMSCs of the tibia indicated that BMSCs of different sources had different biological characteristics. BMSCs from the two abovementioned sources exhibited differences in their ability of bone formation and proliferation, with the osteogenic abilities of neural crest-derived BMSCs being greater due to the differences in embryonic origin and HOX gene expression in the process of bone regeneration (4). Furthermore, the jaw and skeletal limbs have different patterns of bone formation, which proceed via intramembrane osteogenesis in the jaw and via endochondral osteogenesis in skeletal limbs. Gene expression, including mRNA expression, during bone formation and the regulatory mechanisms under any stimulation may be different in bone tissues of these two origins. Previous studies on diabetic osteopathia have mainly focused on cells or tissues derived from skeletal limbs. Even fewer studies have focused on the mechanism of diabetes-associated pathological changes in the jaw, in which teeth are anchored and with which dental implants are combined.

MicroRNAs (miRNAs/miRs) are noncoding single-stranded RNA molecules consisting of $\sim 22$ nucleotides. miRNAs are widely distributed in all types of organisms. By binding to the 3'-untranslated region (3'-UTR) of the mRNA of a target gene, miRNAs may cause their degradation or translational repression $(5,6)$ and post-transcriptionally regulate the process of gene expression, which is associated with individual growth, development and diseases. Various miRNAs have important roles in numerous human diseases, including diabetes, and are aberrantly expressed in affected patients/tissues. Studies have 
indicated that certain miRNAs are important in the maintenance of bone development and metabolism. They regulate osteogenesis by modulating osteogenic transcription factors and their associated factors. A group of miRNAs, including miR-133, miR-23a and miR-30c, have been reported to inhibit osteogenesis by targeting the key transcription factor Runt-related protein 2 (Runx2) (7-12). Another group of miRNAs, including miR-145, miR-214 and miR-31, inhibit osteogenesis by targeting Osterix (13-18). Distal-less homeobox 5, special AT-rich sequence-binding protein 2 and other associated factors have been reported to be the targets of miRNAs (19-21). miRNA also regulates osteogenesis-associated signaling pathways to regulate bone formation. Bone morphogenetic protein (BMP)/transforming growth factor (TGF)- $\beta$ and Wnt signaling pathways have been widely reported to be regulated by a group of miRNAs. miR-29b, miR-135a and miR-199a have been reported to inhibit osteogenesis by targeting factors of the BMP/TGF- $\beta$ pathway (8,22-25), while miR-335-5p, miR-29a and miR-27a regulate osteogenesis by targeting factors associated with the Wnt pathway (26-29). While numerous factors and pathways associated with osteogenesis that have been identified to be regulated by miRNAs (30), only few studies have assessed miRNA expression in the jaw bone, and it has therefore remained elusive whether miRNAs are involved in loss of alveolar bone and osteoporosis of the jaw in diabetes.

The present study intended to i) determined whether miRNAs have a role in the regulation of bone loss in the jaw bone in T2DM, and ii) investigate the underlying mechanisms. The results indicated that the expression of a group of miRNAs in the mandibles of diabetic rats is different from that in the mandibles of normal rats. For the first time, to the best of our knowledge, miR-203-3p was identified to be upregulated in the diabetic group and to participate in osteogenesis inhibition. Subsequently, miR-203-3p was indicated to target the 3'-UTR of Smad1 mRNA, the protein of which is an important mediator of the BMP/Smad pathway, and to thereby inhibit Smad1 expression and degrade Smad1 mRNA. Therefore, the BMP/Smad pathway was repressed by miR-203-3p. The present study provided a basis for a gene therapeutic approach by inhibition of miR-203-3p in diabetic jaw bones, which may ameliorate diabetic osteoporosis and improve fracture healing, tooth stability and implant osseointegration.

\section{Materials and methods}

Experimental animals. A total of 6 male Sprague Dawley (SD) rats (age, 10 weeks; weight, 290-310 g) were purchased from the Experimental Animal Center of Chongqing Medical University (Chongqing, China). The rats were maintained in the same room under a 12-h light/dark cycle (lights on at 08:00 a.m.; 150 lux) with $60 \pm 10 \%$ relative humidity and an ambient temperature of $25 \pm 2^{\circ} \mathrm{C}$ in barrier conditions. The rats had access to sterile chow and water ad libitum in a specific pathogen-free facility in Chongqing Key Laboratory of Oral Diseases and Biomedical Sciences (Chongqing, China). The rats were randomly assigned to a diabetic group and control group. The diabetic group was treated by intraperitoneal injection of streptozotocin (STZ; $30 \mathrm{mg} / \mathrm{kg}$ body weight; Sigma-Aldrich; Merck KGaA, Darmstadt, Germany) and was fed a high-fat diet, which was composed of $66.5 \%$ basic feed,
$20 \%$ sucrose, $10 \%$ lard, $2.5 \%$ cholesterol and $1 \%$ cholic acid salt, for 8 weeks. Rats were considered to be diabetic when their blood glucose levels exceeded $16.7 \mathrm{mmol} / \mathrm{l}$ at 8 weeks after injection. The control group was injected with saline instead of STZ and was fed a normal diet. Another 3 male SD rats (age, 8 weeks; weight, 270-280 g) were used for isolation of rat (r) BMSCs. The study was approved by the Ethics Committee of Chongqing Medical University (Chongqing, China).

Bone collection. Three rats of each group were sacrificed after 8 weeks. Left and right mandibles of every rat were isolated within 5 min and washed with PBS (Gibco; Thermo Fisher Scientific, Inc., Waltham, MA, USA). After the teeth were extracted, the mandibles were placed into liquid nitrogen and transferred into cryogenic vials (Corning Inc., Corning, NY, USA) and stored at $-80^{\circ} \mathrm{C}$.

Cell culture and differentiation. rBMSCs were isolated from 3 male SD rats (age, 8 weeks). The bone marrow of the mandibles was flushed out with $\alpha$-Modified Eagle's Medium ( $\alpha$-MEM; Gibco; Thermo Fisher Scientific, Inc.) containing $20 \%$ fetal bovine serum (FBS; Gibco; Thermo Fisher Scientific, Inc.) and seeded in $60-\mathrm{mm}$ dishes. After $72 \mathrm{~h}$ of incubation, the medium was removed and the non-adherent cells were removed by washing with PBS (Gibco; Thermo Fisher Scientific, Inc.). The adherent cells were further cultured with $\alpha$-MEM containing $10 \%$ FBS and passaged twice a week at a 1:3 ratio, and cells at passage 3-4 were used in the subsequent experiments. $\mathrm{C} 3 \mathrm{H} 101 / 2$ clone 8 cells from the American Type Culture Collection (Manassas, VA, USA) were cultured in Dulbecco's modified Eagle's medium (DMEM; Gibco; Thermo Fisher Scientific, Inc.) containing 10\% FBS. rBMSCs or $\mathrm{C} 3 \mathrm{H} 101 / 2$ cells were seeded in 24- or 6-well plates and induced using osteogenic medium with 5.5 or $25 \mathrm{mM}$ glucose plus $50 \mu \mathrm{g} / \mathrm{ml}$ ascorbic acid, $10 \mathrm{nM}$ dexamethasone and $10 \mathrm{mM} \beta$-glycerophosphate. After 7 days, the RNA or protein was extracted at the indicated times, and the cells were fixed in $4 \%$ paraformaldehyde for histochemical detection of alkaline phosphatase (ALP) (31).

RNA preparation. The mandibles were ground in liquid nitrogen. The total RNA of mandibles and cells was isolated with TRIzol reagent (Ambion; Thermo Fisher Scientific, Inc.) according to the manufacturer's instructions. The quality of the RNA samples for high-throughput deep sequencing was determined with a Bioanalyzer 2100 (Agilent Technologies, Inc., Santa Clara, CA, USA), and the purity of the RNA samples for reverse transcription-quantitative polymerase chain reaction (RT-qPCR) was determined by measuring the absorbance at 260/280 nm with a Nanodrop spectrophotometer (NanoDrop; Thermo Fisher Scientific, Inc.).

High-throughput small RNA sequencing. After the left sides of the mandibles of 3 rats of each group were ground into powder in liquid nitrogen, the RNA was isolated with TRIzol reagent (Ambion; Thermo Fisher Scientific, Inc.) according to the manufacturer's instructions. The RNA was subjected to high-throughput small RNA sequencing, which was performed by the Beijing Genomics Institute (Shenzhen, China). RNA (18-30 nt) was isolated by PAGE and sequentially ligated to 
Table I. Sequences of reverse transcription primers for miRs.

\begin{tabular}{ll}
\hline Gene name & Sequence $\left(5^{\prime}-3^{\prime}\right)$ \\
\hline miR-203a-3p & GTCGTATCCAGTGCAGGGTCCGAGGTATTCGCACTGGATACGACCTAGTG \\
miR-23a-3p & GTCGTATCCAGTGCAGGGTCCGAGGTATTCGCACTGGATACGACGGAAAT \\
miR-96-5p & GTCGTATCCAGTGCAGGGTCCGAGGTATTCGCACTGGATACGACAGCAAA \\
miR-30c-5p & GTCGTATCCAGTGCAGGGTCCGAGGTATTCGCACTGGATACGACGCTGAG \\
miR-17-5p & GTCGTATCCAGTGCAGGGTCCGAGGTATTCGCACTGGATACGACCTACCT \\
miR-320-3p & GTCGTATCCAGTGCAGGGTCCGAGGTATTCGCACTGGATACGACTCGCCC
\end{tabular}

miR, microRNA.

5' and 3' small RNA adapters. The 5' adapter ligation reaction was performed at $20^{\circ} \mathrm{C}$ for $6 \mathrm{~h}$, and RNA (40-60 nt) was isolated by PAGE and recycled. Following this, the $3^{\prime}$ adapter ligation reaction was performed at $20^{\circ} \mathrm{C}$ for $6 \mathrm{~h}$, and RNA (60-800 nt) was isolated by PAGE and recycled. Complementary DNA (cDNA) was then synthesized and amplified using proprietary RT primers and amplification primers (Illumina, Inc., San Diego, CA, USA). The reverse transcription reaction was performed as follows: $65^{\circ} \mathrm{C}$ for $10 \mathrm{~min}, 48^{\circ} \mathrm{C}$ for $3 \mathrm{~min}, 42^{\circ} \mathrm{C}$ for $1 \mathrm{~h}$ and $70^{\circ} \mathrm{C}$ for 15 min with First Strand Master Mix (Invitrogen; Thermo Fisher Scientific, Inc.) and SuperScript ${ }^{\mathrm{TM}}$ II (Invitrogen; Thermo Fisher Scientific, Inc.). Several rounds of PCR amplification were performed to enrich the cDNA fragments as follows: $98^{\circ} \mathrm{C}$ for $30 \mathrm{sec}, 12-15$ cycles of $98^{\circ} \mathrm{C}$ for $10 \mathrm{sec}$ and $72^{\circ} \mathrm{C}$ for $15 \mathrm{sec}$, followed by $72^{\circ} \mathrm{C}$ for $10 \mathrm{~min}$ and $4^{\circ} \mathrm{C}$ hold. Subsequently, PCR-amplified fragments were extracted and purified using PAGE. The cDNA libraries were qualified and quantified with an Agilent 2100 Bioanalyzer (Agilent Technologies, Inc.) and an ABI StepOnePlus Real-Time PCR machine (Thermo Fisher Scientific, Inc.). The 49-nt sequence tags from Hiseq sequencing were subjected to data cleaning analysis to obtain credible clean tags. The difference in expression between the diabetic group and the control group was analyzed. miRNA expression levels were visualized by heatmaps generated by $\mathrm{R}$ 3.1.2. TargetScan (http://www.TargetScan.org), miRanda (http://www.microRNA. org) and Pictar (http://pictar.mdc-berlin.de) were used to search for predicted miRNA targets.

$R T$-qPCR assay. Total RNA isolated from the right sides of the mandibles was used for RT-qPCR analysis. The indicated miRNA RT primer was designed for each selected miRNA, which was differentially expressed in the diabetic group and control group detected by high-throughput small RNA sequencing (Table I). The cDNA of miRNA was obtained according to the instructions of the GoScript ${ }^{\mathrm{TM}}$ Reverse Transcription system (Promega Corp., Madison, WI, USA). Equal amounts of cDNA were used in duplicate and amplified with GoTaq ${ }^{\circledR}$ qPCR Master Mix (Promega Corp.). U6 small nuclear RNA was used as an internal reference. The primers used for qPCR are displayed in Table II.

The RNA isolated from mandibles or cells was also processed using the GoScript ${ }^{\mathrm{TM}}$ Reverse Transcription system (Promega Corp.) with OligodT as the primer. The subsequent qPCR was performed according to the instructions of the GoTaq $^{\circledR}$ qPCR Master Mix. $\beta$-actin was used as an internal
Table II. Sequences of primers used for polymerase chain reaction analysis of miRs.

\begin{tabular}{ll}
\hline Gene name & \multicolumn{1}{c}{ Sequence (5'-3') } \\
\hline miR-203a-3p (F) & GCGCGTGAAATGTTTAGGAC \\
miR-23a-3p (F) & TGCATCACATTGCCAGGG \\
miR-96-5p (F) & TCGTTTGGCACTAGCACATT \\
miR-30c-5p (F) & GCGCTGTAAACATCCTACACT \\
miR-17-5p (F) & CGCAAAGTGCTTACAGTGC \\
miR-320-3p (F) & CGCAAAAGCTGGGTTGAGA \\
miRNA (R) & GTGCAGGGTCCGAGGT \\
U6 (F) & CTCGCTTCGGCAGCACA \\
U6 (R) & AACGCTTCACGAATTTGCGT
\end{tabular}

miR, microRNA; F, forward; R, reverse.

reference. The forward and reverse PCR primers are displayed in Table III.

All PCRs were performed with a Bio-Rad CFX Manager (Bio-Rad Laboratories, Inc., Hercules, CA, USA). The cycling profile consisted of an initial denaturation at $95^{\circ} \mathrm{C}$ for $10 \mathrm{~min}$, followed by 40 cycles of $95^{\circ} \mathrm{C}$ for $15 \mathrm{sec}, 60^{\circ} \mathrm{C}$ for $60 \mathrm{sec}$ and $95^{\circ} \mathrm{C}$ for $15 \mathrm{sec}$, followed by melt curve analysis. RNA fold changes between different groups were calculated by the $2^{-\Delta \Delta C q}$ method (32).

Western blot analysis. Cells were washed with pre-cooled PBS twice and treated with radioimmunoprecipitation assay buffer (RIPA; Beyotime Institute of Biotechnology, Haimen, China) containing $1 \mathrm{mM}$ phenylmethane sulfonyl fluoride and phosphatase inhibitor (Beyotime Institute of Biotechnology) for $5 \mathrm{~min}$, and the cells and the lysates were collected and centrifuged at $4^{\circ} \mathrm{C}$ for $10 \mathrm{~min}$ at $13,400 \mathrm{x} \mathrm{g}$. The supernatant was collected in fresh tubes, and the concentration was detected with a BCA protein assay kit (Beyotime Institute of Biotechnology) according to the manufacturer's instructions. After the concentration of every sample was adjusted with RIPA, the samples were added to loading buffer (WB0091; Beijing Dingguo Changsheng Biotechnology Co., Ltd., Beijing, China) and boiled for $5 \mathrm{~min}$. The treated samples were stored at $-80^{\circ} \mathrm{C}$ for further analysis. For western blot analysis, total protein $(50 \mu \mathrm{g}$ per lane) was separated using $10 \%$ SDS-PAGE according to 
Table III. Sequences of primers used for polymerase chain reaction analysis of mRNAs.

\begin{tabular}{lll}
\hline Gene name & \multicolumn{1}{c}{ Forward (5'-3') } & \multicolumn{1}{c}{ Reverse (5'-3') } \\
\hline$\beta$-actin $(\mathrm{m})$ & CAGCCTTCCTTCTTGGGTAT & TGGCATAGAGGTCTTTACGG \\
Runx2 $(\mathrm{m})$ & GGGAACCAAGAAGGCACAGA & GGATGAGGAATGCGCCCTAA \\
Smad $(\mathrm{m})$ & CAGAGGAGATGTTCAGGCAGTT & CTGTGAAACCATCCACCAGC \\
ALP $(\mathrm{m})$ & TCGGAACAACCTGACTGACC & GTCAATCCTGCCTCCTTCCA \\
Osterix $(\mathrm{m})$ & TGCTTGAGGAAGAAGCTCACTA & TGAAAGGTCAGCGTATGGCT \\
OC $(\mathrm{m})$ & ACCTCACAGATGCCAAGCC & GCCGGAGTCTGTTCACTACC \\
$\beta$-actin $(\mathrm{r})$ & CCCGCGAGTACAACCTTCTTG & GTCATCCATGGCGAACTGGTG \\
Col1al $(\mathrm{r})$ & AAGTCTCAAGATGGTGGCCG & TACTCTCCGCTCTTCCAGTCA \\
Runx2 $(\mathrm{r})$ & CCGAGACCAACCGAGTCATTTA & AAGAGGCTGTTTGACGCCAT \\
Smad1 $(\mathrm{r})$ & TCAATAGAGGAGATGTTCAAGCAGT & GAAACCATCCACCAACACGC \\
ALP $(\mathrm{r})$ & CCTGCAGGATCGGAACGTCAATTA & TGAGTTGGTAAGGCAGGGTCC \\
Osterix $(\mathrm{r})$ & GCCAGTAATCTTCGTGCCAG & TAGTGAGCTTCTTCCTGGGGA \\
OC $(\mathrm{r})$ & CTCAACAATGGACTTGGAGCC & GGCAACACATGCCCTAAACG
\end{tabular}

m, mouse; r, rat; Runx2, runt-related transcription factor 2; OC, osteocalcin; P, phosphate; Col1a1, collagen type $1 \alpha$ 1; ALP, alkaline phosphatase

the instructions of the SDS-PAGE preparation gel kit (Beijing Dingguo Changsheng Biotechnology Co., Ltd.), followed by transfer onto polyvinylidene difluoride membranes (EMD Millipore, Billerica, MA, USA). The membranes were blocked using Tris/HCl-buffered salt solution containing $0.1 \%$ Tween-20 and $5 \%$ bovine serum albumin (Sigma-Aldrich; Merck KGaA) for $2 \mathrm{~h}$ at room temperature. The membranes were incubated with specific antibodies to Runx2 (1:1,000; cat. no. sc-10758; Santa Cruz Biotechnology, Inc., Dallas, TX, USA), $\beta$-actin $(1: 1,000$; cat. no. 13E5), Smad1 (1:1,000; cat. no. D59D7), phosphorylated (p)-Smad1 (1:1,000; cat. no. D40B7) and p-Smad1/5/8 (1:1,000; cat. no. D5B10; Cell Signaling Technology, Inc., Danvers, MA, USA) overnight at $4^{\circ} \mathrm{C}$. Following this, the membranes were washed three times in $0.1 \%$ TBST and incubated for $1.5 \mathrm{~h}$ with the secondary antibody (1:2,000; cat. no. A21020-1; Abkine, Wuhan, HB, China) at room temperature. Blots were developed using an enhanced chemiluminescence (ECL) kit (BeyoECL Plus; Beyotime Institute of Biotechnology), and images were captured using a Bio-Rad Moleculer Imager ${ }^{\circledR}$ ChemiDoc $^{\mathrm{TM}}$ XRS Imaging system (Bio-Rad Laboratories, Inc.). Densitometry was performed with Quantity One ${ }^{\circledR}$ Software v. 4.6.9 (Bio-Rad Laboratories, Inc.).

Plasmid construction. Plasmid construction was performed by Lengshuiquan Biotechnology Co., Ltd. (Chengdu, China). The RNA of mouse livers was extracted and reverse transcribed into cDNA. The wild-type 3'-UTR of Smad1 and a mutated sequence were amplified by PCR using primers with $\mathrm{XbaI}$ and $F s e I$ restriction sites. The wild-type primer sequences were 5'-TGTTCTAGAAGACCTGTGGCTTCCGTCTC TTG-3' (forward) and 5'-AATGGCCGGCCTTATTTAAAA ATTTCCAGTAGAG-3' (reverse), and the mutant primer sequences were 5'-TGTTCTAGAAGACCTGTGGCTTCC GTCTCTTG-3' (forward) and 5'-ATAGAGAGATCTTTA ATCCTGCGAATAATGAAC-3' (reverse). The PCR product was purified and then inserted into the XbaI-FseI site of the pGL3-control vector (Promega, Madison, WI, USA), and it was identified by DNA sequencing. The wild-type plasmid containing the 3'-UTR of Smad1 with the complementary sequence of miR-203-3p (pGL3-Smad1 3'-UTR WT) and the mutant plasmid with the mutation sequence containing the 3'-UTR of Smad1 without the complementary sequence of miR-203-3p (pGL3-Smad1 3'-UTR mut) were created.

To construct a Smad1 expression vector, cytomegaloviral vector (pCMV)-Smad1, the Smad1 coding sequence was RT-PCR-amplified from mouse mRNA using the primer sequences 5'-GTGTAGAATTCGACCAGCCGCTATGAA TGT-3' (forward) and 5'-TTTGCTCGAGACGGAAGCCAC AGGTC-3' (reverse). The PCR product was digested with EcoRI-XbaI and sub-cloned into the similarly digested pCMV vector (Invitrogen; Thermo Fisher Scientific, Inc.). The plasmids were sequenced to ensure authenticity.

miRNA and plasmid transfection. Prior to transfection, cells were seeded into 6-well or 24-well plates and were transfected at 50-70\% confluence. Agomir-203-3p, Agomir-NC, Antagomir-203-3p and Antagomir-NC were purchased from GenePharma Co., Ltd. (Shanghai, China) and were transfected into indicated cells at a concentration of $100 \mathrm{nM}$ with Lipofectamine ${ }^{\circledR} 2000$ (Invitrogen; Thermo Fisher Scientific, Inc.) in Opti-MEM ${ }^{\circledR}$ (Gibco; Thermo Fisher Scientific, Inc.). Smad1 overexpression plasmids were transfected into cells at $1 \mu \mathrm{g}$ per well for 24-well plates or $4 \mu \mathrm{g}$ per well for 6 -well plates. After $6 \mathrm{~h}$ of transfection, the Opti-MEM ${ }^{\circledR}$ was replaced by medium with $10 \%$ FBS.

Luciferase reporter assay. C3H10T1/2 cells were seeded in 24-well plates, co-transfected with three luciferase constructs containing pGL3-Smad1 3'-UTR wild or mut, phRL-null (Renilla plasmid for normalization) and $100 \mathrm{~nm}$ Agomir-203-3p or Agomir-NC. Luciferase assays were performed using the Promega Dual Luciferase Assay system (cat. no. E1910; Promega Corp.) according to the manufacturer's instructions. Three independent experiments were performed for $24 \mathrm{~h}$ 

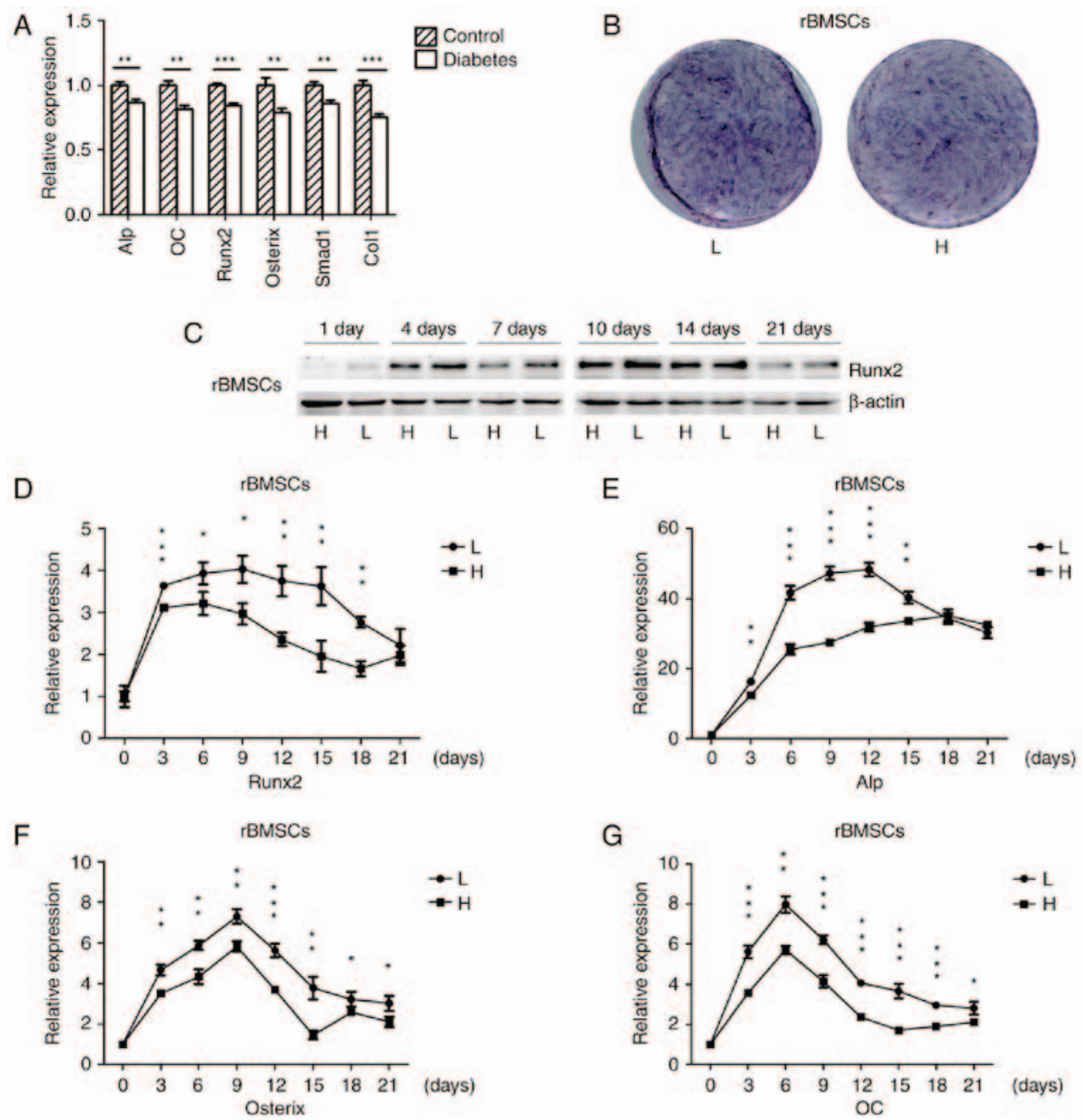

Figure 1. Osteogenesis is downregulated in the mandibles of diabetic rats and high-glucose-treated rBMSCs. (A) RT-qPCR analysis of the mRNA expression of ALP, OC, Runx2, Osterix, Smad1 and Coll in the mandibles of high-fat diet- and STZ-induced type 2 diabetic, as well as in normal rats. (B) Histochemical detection of ALP of osteogenically-induced rBMSCs in high-glucose or normal medium on day 7 of culture. (C) Protein expression of Runx 2 in rBMSCs osteogenically induced for 1, 4, 7, 10, 14 and 21 days was detected by western blot analysis. (D-G) RT-qPCR analysis of mRNA expression of Runx2, ALP, Osterix and OC in rBMSCs osteogenically induced in high-glucose and low-glucose medium for 0, 3, 6, 9, 12, 15, 18 and 21 days. Values are expressed as the mean \pm standard deviation $(\mathrm{n}=3)$. ${ }^{*} \mathrm{P}<0.05,{ }^{* *} \mathrm{P}<0.01,{ }^{* * * *} \mathrm{P}<0.001$. RT-qPCR, reverse transcription-quantitative polymerase chain reaction; L, low-glucose medium; H, high-glucose medium; rBMSCs, rat bone marrow mesenchymal stem cells; ALP, alkaline phosphatase; Runx2, runt-related transcription factor 2; Coll, collagen type $1 \propto 1$; OC, osteocalcin.

and assayed in quadruplicate per group. Relative luciferase activity (firefly/Renilla) was detected with a Promega Glomax (Promega Corp.).

Statistical analysis. GraphPad Prism 5 software (GraphPad Software, Inc., La Jolla, CA, USA) was used for all statistical tests. Values are expressed as the mean \pm standard deviation. For comparisons between 2 groups, a two-tailed Student's t-test was used. For comparisons between multiple groups, one-way analysis of variance followed by Tukey's test was applied. RT-qPCR assays, western blot analysis and luciferase reporter assays were repeated at least three times and representative results are presented. $\mathrm{P}<0.05$ was considered to indicate a statistically significant difference.

\section{Results}

Osteogenesis is downregulated in the mandibles of diabetic rats and high-glucose-treated rBMSCs. The mRNA expression of osteogenic genes in the mandibles of SD rats with high-fat dietand STZ-induced T2DM as well as in normal rats was detected by RT-qPCR. The osteogenic genes were significantly downregulated in the mandibles of diabetic rats (Fig. 1A), which was consistent with the results of another study (33). rBMSCs were osteogenically induced in high-glucose or normal medium, and the histochemical detection of ALP on day 7 indicated that ALP expression was downregulated in cells grown in high-glucose medium (Fig. 1B). The protein expression of the osteogenic key transcriptional factor Runx2 in cells cultured in high-glucose medium was downregulated on days 1, 4, 7, 10, 14 and 21 (Fig. 1C), and the mRNA expression of osteogenic genes was also downregulated during osteogenesis; however, towards the end of the in vitro experiment there was no significant difference for Runx2 and Alp (Fig. 1D-G). These results suggested that diabetes and high glucose levels repress osteogenesis.

Changes of miRNA expression in mandibles of diabetic rats. A number of miRNAs has been verified to regulate osteogenesis in 


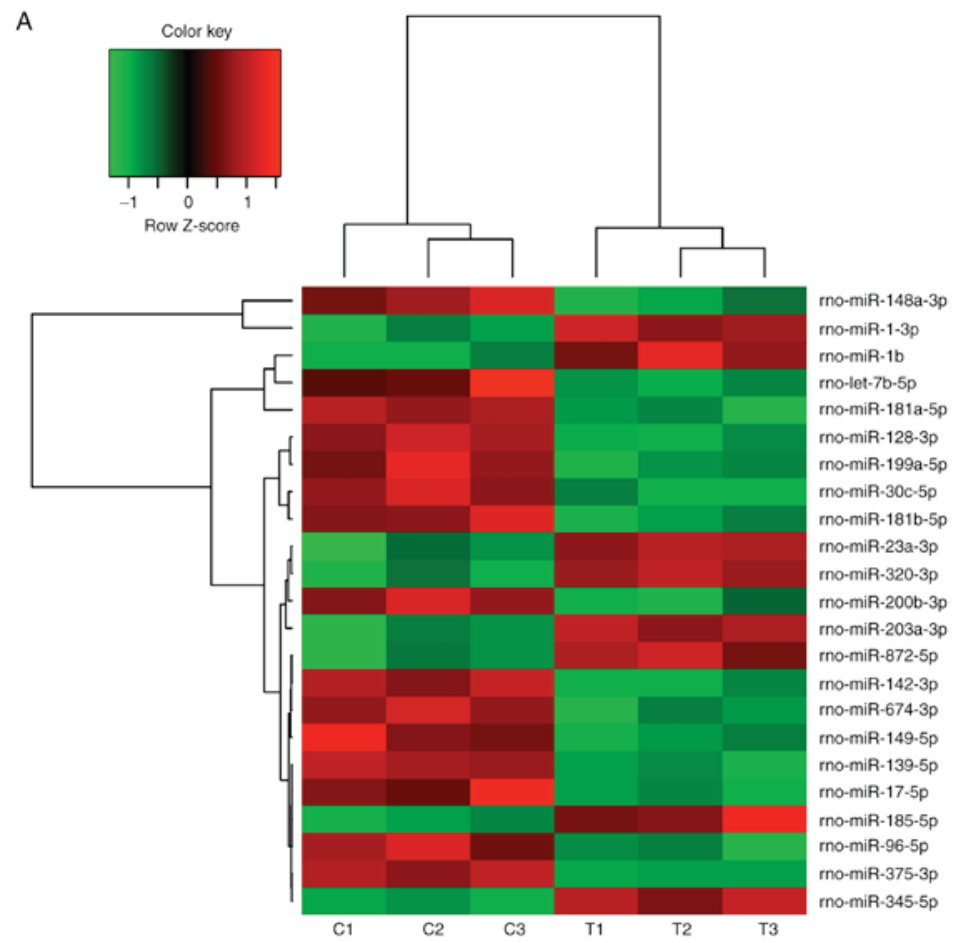

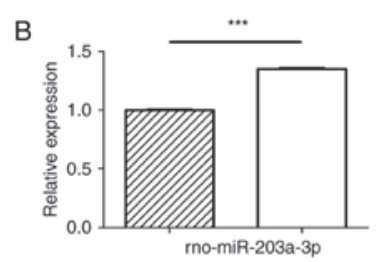

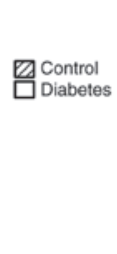

D
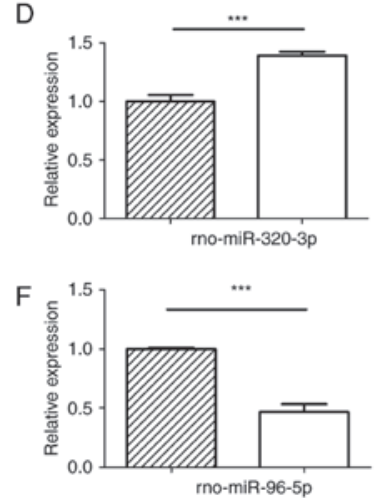

C

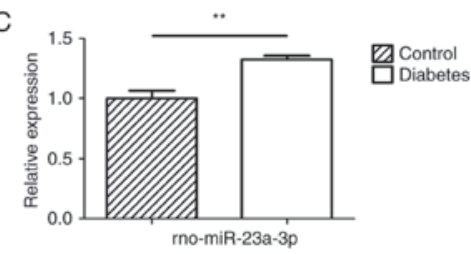

E
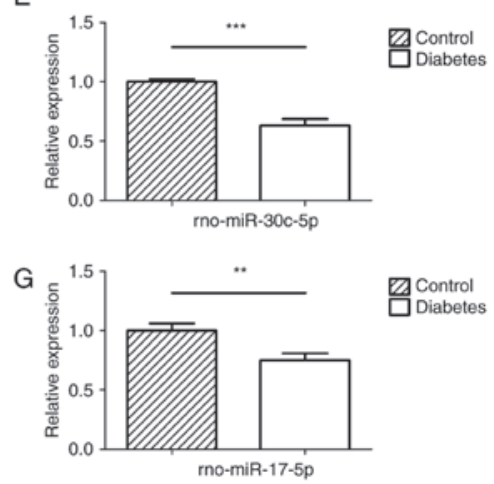

Figure 2. Changes of miRNA expression in mandibles of diabetic rats. (A) High-throughput small RNA sequencing results of differently expressed miRNAs in mandibles of control and diabetic rats. (B-G) High-throughput small RNA sequencing results of (B) miR-203a-3p, (C) miR-23a-3p, (D) miR-320-3p, (E) miR-30c-5p, (F) miR-96-5p and (G) miR-17-5p were validated by reverse transcription-quantitative polymerase chain reaction. Values are expressed as the mean \pm standard deviation $(\mathrm{n}=3) .{ }^{* *} \mathrm{P}<0.01,{ }^{* * *} \mathrm{P}<0.001$. miR/miRNA, microRNA; rno, Rattus norvegicus; $\mathrm{C} 1-3$, control rat 1-3; T1-3, testing rat (diabetic rat) 1-3.

various studies (30). In a previous study, the miR-17 92 cluster was reported to critically regulate osteoblast differentiation (26). Therefore, the present study used high-throughput small RNA sequencing to detect any differences in miRNA expression between experimental T2DM rats and normal rats. The heat map indicates that 126 miRNAs were differently expressed between the two groups of rats (Fig. 2A). RT-qPCR was performed to verify these results on the miRNAs from the high-throughput sequencing. miR-30c-5p, miR-96-5p and miR-17-5p were downregulated in the diabetic group, while miR-203a-3p, miR-23a-3p and miR-320-3p were upregulated (Fig. 2B-G), which was consistent with the results of the high-throughput sequencing.
Gain- and loss-of-function analyses. Agomir-203-3p, antagomir-203-3p and their negative control were transfected into C3H10T1/2 cells or rBMSCs (Fig. 3A). Cells were osteogenically induced and fixed in $4 \%$ paraformaldehyde for histochemical detection of ALP on day 7. Histological staining for ALP, an early marker of bone formation, revealed that miR-203-3p reduced ALP and inhibited osteogenesis (Fig. 3B). The protein expression of the key transcriptional factor Runx2 was inhibited by miR-203-3p and promoted by the inhibitor of miR-203-3p on days 4, 7 and 14 of osteogenesis (Fig. 3C). The mRNA expression of several osteogenic genes was detected by RT-qPCR on days 1, 4, 7 and 14 (Fig. 3D-G). The expression of 

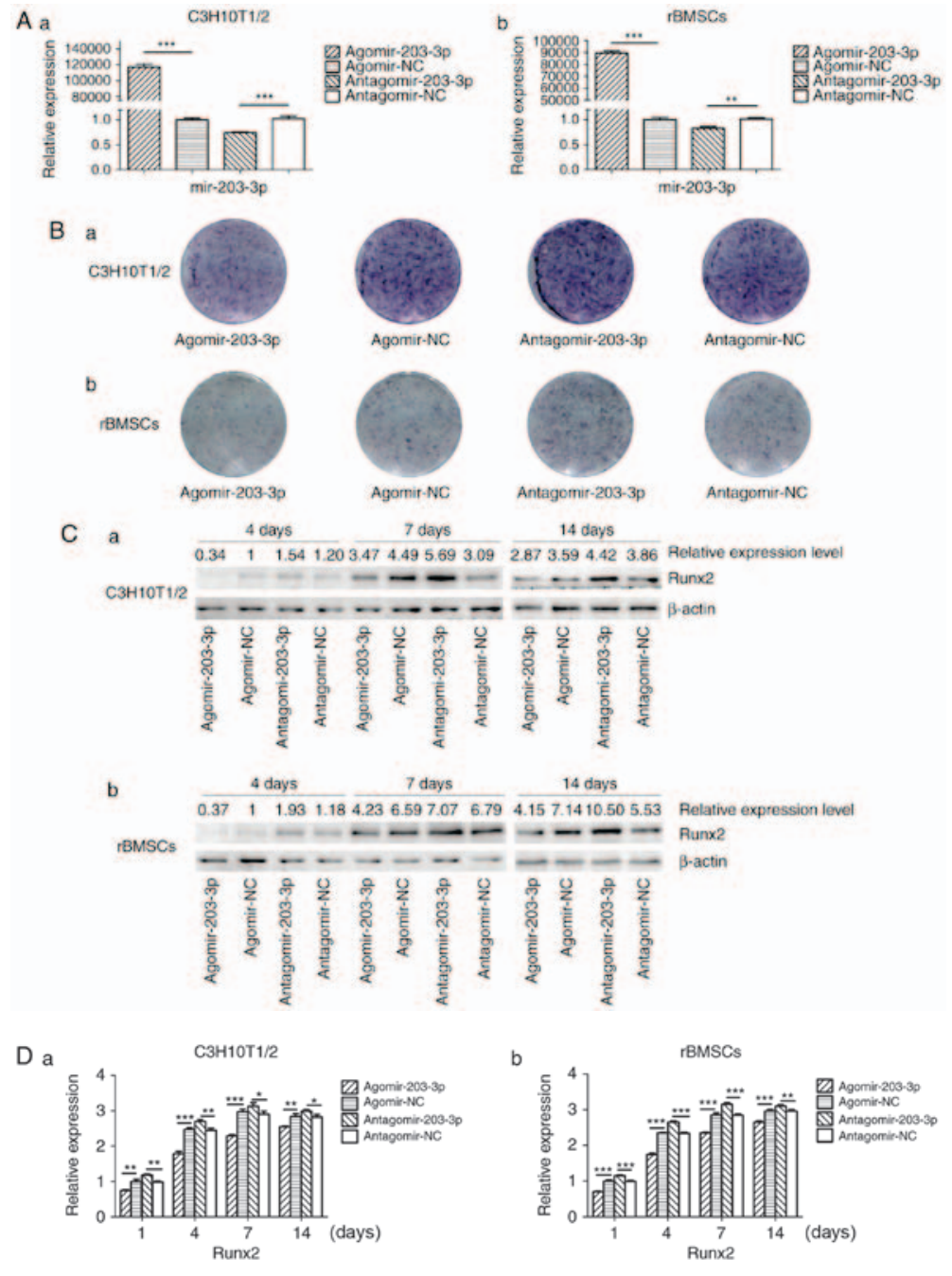

E a
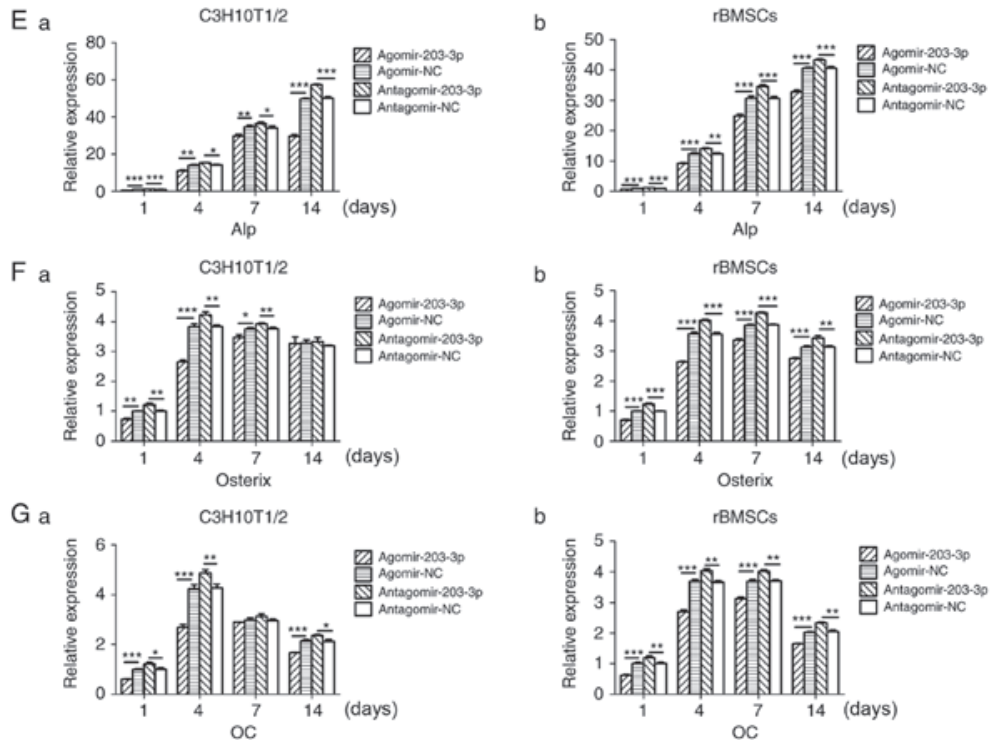

Figure 3. Gain- and loss-of-function experiments. (A) RT-qPCR analysis of levels of miR-203-3p expression in (a) C3H10T1/2 cells and (b) rBMSCs transfected with agomir-203-3p, agomir-NC, antagomir-203-3p and antagomir-NC. (B) Cells were osteogenically induced and fixed in 4\% paraformaldehyde for histochemical detection of ALP after 7 days of culture. Representative histological staining images (magnification, x1.4) for ALP (ALP staining) of (a) C3H10T1/2 cells and (b) rBMSCs transfected with agomir-203-3p, agomir-NC, antagomir-203-3p and antagomir-NC are displayed. (C) Protein expression of Runx2 in (a) C3H10T1/2 cells and (b) rBMSCs transfected with agomir-203-3p, agomir-NC, antagomir-203-3p and antagomir-NC after 4, 7 and 14 days of osteogenic induction detected by western blot analysis, revealing that miR-203-3p inhibited the expression of Runx2, while the inhibitor of miR-203-3p promoted its expression. (D-G) The mRNA expression of (D) Runx2, (E) ALP, (F) Osterix and (G) OC in (a) C3H10T1/2 cells and (b) rBMSCs transfected with agomir-203-3p, agomir-NC, antagomir-203-3p and antagomir-NC after 1, 4, 7 and 14 days of osteogenic induction was detected by RT-qPCR. The expression of Runx2 and ALP was inhibited by miR-203-3p and promoted by its inhibitor, while the expression of Osterix and OC was retarded by miR-203-3p and promoted by its inhibitor. Values are expressed as the mean \pm standard deviation $(n=3) .{ }^{*} \mathrm{P}<0.05,{ }^{* *} \mathrm{P}<0.01,{ }^{* * *} \mathrm{P}<0.001$. miR, microRNA; RT-qPCR, reverse transcription-quantitative polymerase chain reaction; rBMSCs, rat bone marrow mesenchymal stem cells; ALP, alkaline phosphatase; Runx2, runt-related transcription factor 2; OC, osteocalcin; NC, negative control; Agomir, miR agonist; Antagomir, miR antagonist. 

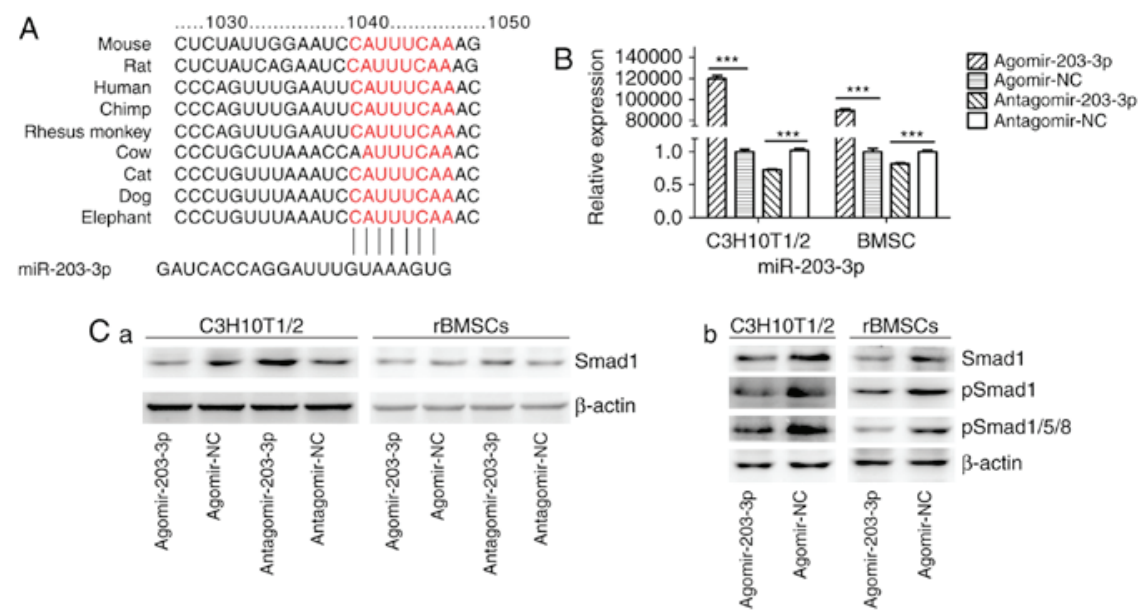

$\mathrm{Da}$

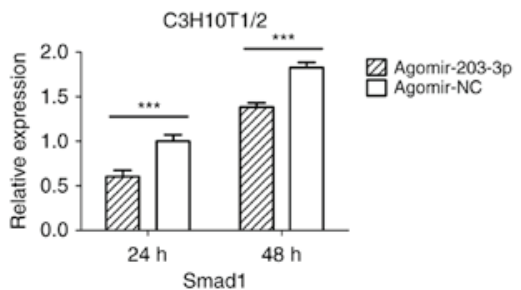

b

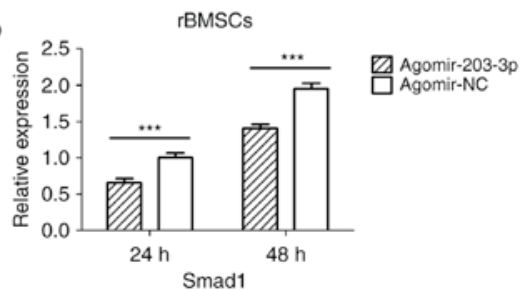

E a

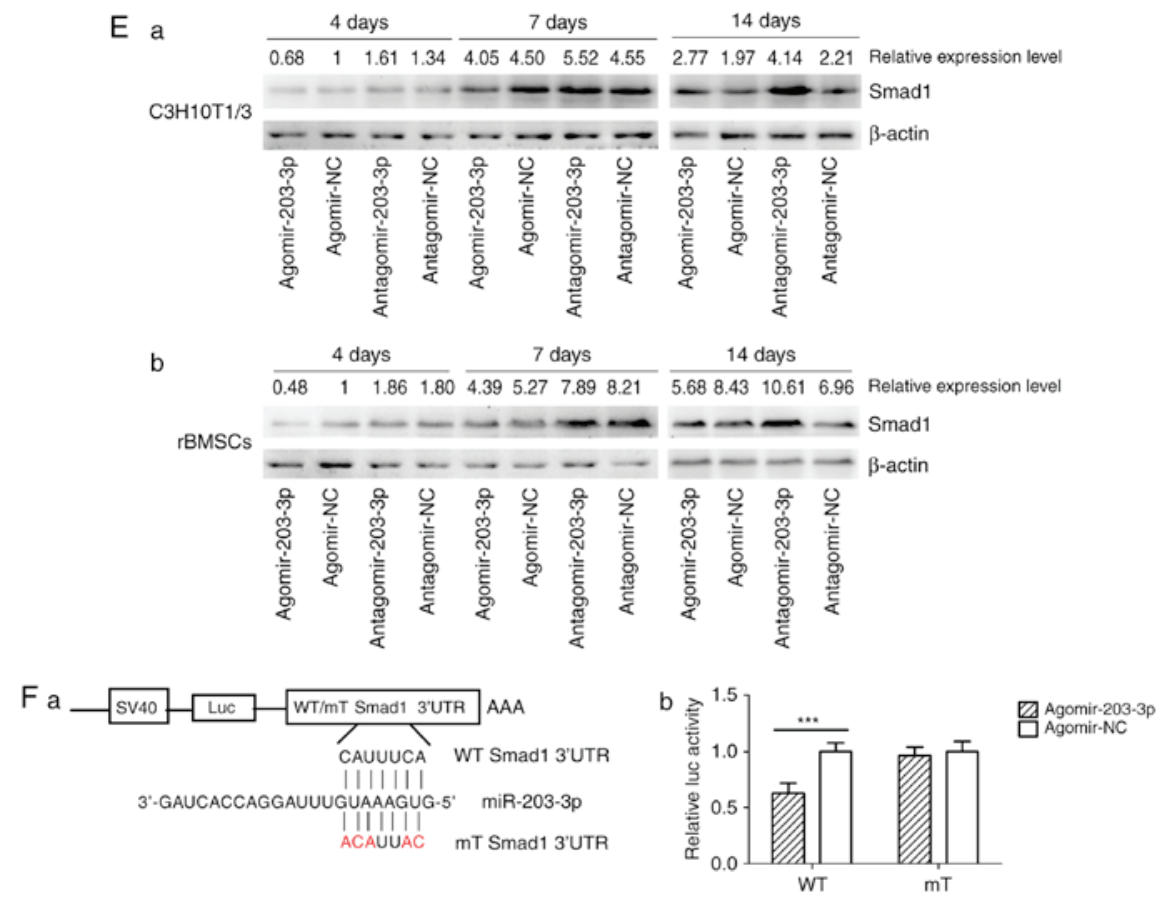

14 days

Figure 4. miR-203-3p targeting the Smad1 gene. (A) A putative target site of miR-203-3p, which is highly conserved in mammals, was predicted to be located in the 3'-UTR of Smad1 mRNA, by using TargetScan software. The numbers represent the position of the 'seed region' matching miR-203-3p within the 3'-UTR sequences. (B) Reverse transcription-quantitative polymerase chain reaction analysis of levels of miR-203-3p expression in C3H10T1/2 cells and rBMSCs transfected with agomir-203-3p, agomir-NC, antagomir-203-3p and antagomir-NC. (C) Protein was extracted at $48 \mathrm{~h}$ after transfection. (a) Western blot analysis demonstrated that the protein levels of Smad1 were repressed by overexpression of miR-203-3p and promoted by inhibition of miR-203-3p. (b) Expression of bone morphogenetic protein/Smad pathway-associated proteins in C3H10T1/2 cells and rBMSCs. Representative western blot images demonstrate that Smad1, p-Smad1 and p-Smad1/5/8 levels are repressed by overexpression of miR-203-3p. (D) mRNA was extracted at 24 and $48 \mathrm{~h}$ after transfection. The mRNA expression of Smad1 was depressed by overexpression of miR-203-3p in (a) C3H10T1/2 cells and (b) rBMSCs. (E) Smad1 protein levels in (a) C3H10T1/2 cells and (b) rBMSCs transfected with agomir-203-3p, agomir-NC, antagomir-203-3p and antagomir-NC on the days 4, 7 and 14 of osteogenic induction was detected by western blot analysis, revealing that overexpression of miR-203-3p caused the expression of Smad1 to be (a) depressed and retarded in C3H10T1/2 cells and (b) to be depressed in rBMSCs. Overexpression of miR-203-3p suppressed the expression of Smad1 in (a) C3H10T1/2 cells and (b) rBMSCs, while inhibition of miR-203-3p resulted in the promotion of Smad1. Agomir delayed the expression of Smad1 so that, in the osteogenic process, the Agomir group demonstrated the highest expression levels of Smad1 later than the Agomir-NC group. At day 14, Smad1 appeared to be increased in the Agomir group compared with that observed in the Agomir-NC group. (F-a) A luciferase reporter system containing a binding site (Smad1-3'-UTR-WT) or a mutated site (Smad1-3'-UTR-mut) located in the downstream region of the pGL3 luciferase reporter gene was constructed. C3H10T1/2 cells were co-transfected with pGL3-Smad1 or pGL3-Smad1-mut, phRL-null and Agomir-203-3p or Agomir-NC. (b) Compared with the negative control, the luciferase activity in the group co-transfected with Agomir-203-3p and pGL3-Smad1-WT was decreased by 37.3\%, while Agomir-203-3p did not affect the luciferase activity of the pGL3-Smad1-mut vector. Values are expressed as the mean \pm standard deviation (n=3). ${ }^{\text {*** }} \mathrm{P}<0.001$. miR, microRNA; NC, negative control; Agomir, miR agonist; Antagomir, miR antagonist; UTR, untranslated region; mut/Mt, mutant; WT, wild-type; rBMSCs, rat bone marrow mesenchymal stem cells; pSmad, phosphorylated Smad; Luc, luciferase. 

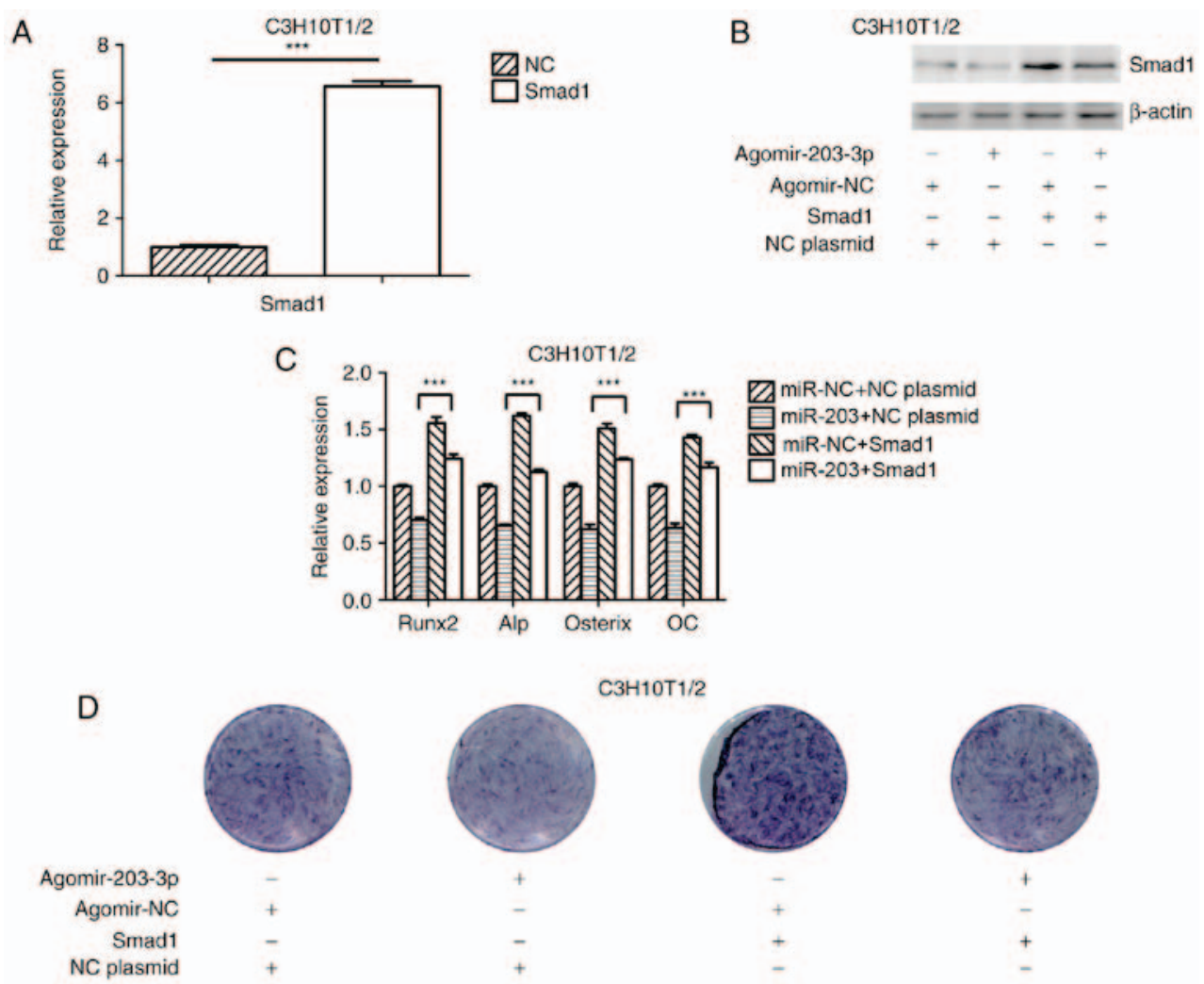

Figure 5. Overexpression of Smad1 rescues the repression of osteogenesis by miR-203-3p. (A) RT-qPCR analysis of levels of Smad1 expression in C3H10T1/2 cells transfected with Smad1 overexpression plasmid and NC plasmid. (B) Smad1 protein expression in C3H10T1/2 cells transfected with Smad1 overexpression plasmid or NC plasmid and agomir-203-3p or agomir-NC was detected by western blot analysis. (C and D) Smad1 overexpression plasmid or NC plasmid and agomir-203-3p or agomir-NC were co-transfected into C3H10T1/2 cells, followed by osteogenic induction for 7 days. (C) RT-qPCR was used to analyze the expression levels of Runx2, Alp, Osterix and OC. (D) Histochemical detection of ALP in C3H10T1/2 cells (magnification, x1.4). Overexpression of Smad1 appeared to attenuate the miR-203-3p-mediated suppression of osteogenic differentiation. Values are expressed as the mean \pm standard deviation $(\mathrm{n}=3) .{ }^{* * *} \mathrm{P}<0.001$. miR, microRNA; NC, negative control; Agomir, miR agonist; Antagomir, miR antagonist; ALP, alkaline phosphatase; Runx2, runt-related transcription factor 2; OC, osteocalcin; RT-qPCR, reverse transcription-quantitative polymerase chain reaction.

Runx 2 and ALP was inhibited by miR-203-3p and promoted by its inhibitor (Fig. 3D and E); similarly, the expression of Osterix and osteocalcin (OC) was retarded by miR-203-3p and promoted by its inhibitor (Fig. 3F and G), which suggested that miR-203-3p inhibits osteogenesis in C3H10T1/2 cells and rBMSCs.

miR-203-3p directly targets Smadl. Using TargetScan software, a putative binding site for miR-203-3p was identified in the 3'-UTR of Smad1 mRNA, which is highly conserved in mammals (Fig. 4A). To determine whether Smad1 is the direct target of miR-203-3p, agomir-203-3p, antagomir-203-3p and their negative control were transfected into in $\mathrm{C} 3 \mathrm{H} 10 \mathrm{~T} 1 / 2$ cells or $\mathrm{rBMSCs}$ (Fig. 4B), and after $48 \mathrm{~h}$ of osteogenesis, the expression of Smad1 was assessed by western blot analysis. The results demonstrated that the protein levels of Smad1 were repressed following enhancement of miR-203-3p and increased following inhibition of miR-203-3p (Fig. 4Ca). The protein levels of further Smads were detected in $\mathrm{C} 3 \mathrm{H} 10 \mathrm{~T} 1 / 2$ cells or rBMSCs. Western blot analysis indicated that enhancement of miR-203-3p obviously repressed the protein levels of Smad1, p-Smad1 and p-Smad1/5/8 in C3H10T1/2 cells or rBMSCs (Fig. 4Cb). Furthermore, the mRNA expression of Smad1 was depressed by overexpression of miR-203-3p in C3H10T1/2 cells and rBMSCs following 24 and $48 \mathrm{~h}$ of osteogenesis (Fig. 4D). Furthermore, enhancement of miR-203-3p suppressed the expression of Smad1 in C3H10T1/2 cells and rBMSCs, while inhibition of miR-203-3p resulted in the promotion of Smad1 at various time-points of osteogenesis. Agomir delayed the expression of Smad1 so that,in the osteogenic process, the Agomir group demonstrated the highest expression levels of Smad1 later than the Agomir-NC group. At day 14, Smad1 appeared to be increased in the Agomir group compared with that observed in the Agomir-NC group (Fig. 4E). To demonstrate the direct interaction between miR-203-3p and Smad1 mRNA, a pGL3 luciferase reporter system containing a binding site (Smad1-3'-UTR WT) or a mutated site (Smad1-3'-UTR mut) located in the downstream region of the luciferase reporter gene was constructed. C3H10T1/2 cells were co-transfected with pGL3-Smad1-WT or pGL3-Smad1-mut, phRL-null and agomir-203-3p or agomir-NC. The luciferase activity of the pGL3-Smad1 vector in the agomir-203-3p group was decreased by $37.3 \%(\mathrm{P}<0.01)$ compared with that in the agomir-NC group, while agomir-203-3p did not affect the luciferase activity of the pGL3-Smad1 mut vector (Fig. 4F). These results were consistent with the bioinformatics prediction that the 3'-UTR of Smad1 mRNA is a direct target of miR-203-3p (Fig. 4A).

Ectopic overexpression of Smadl abrogates the suppressive effect of miR-203-3p on osteogenesis. To further investigate the association between miR-203-3p and Smad1, a Smad1 overexpression plasmid was constructed and transfected into $\mathrm{C} 3 \mathrm{H} 10 \mathrm{~T} 1 / 2$ cells (Fig. 5A); in addition, the 


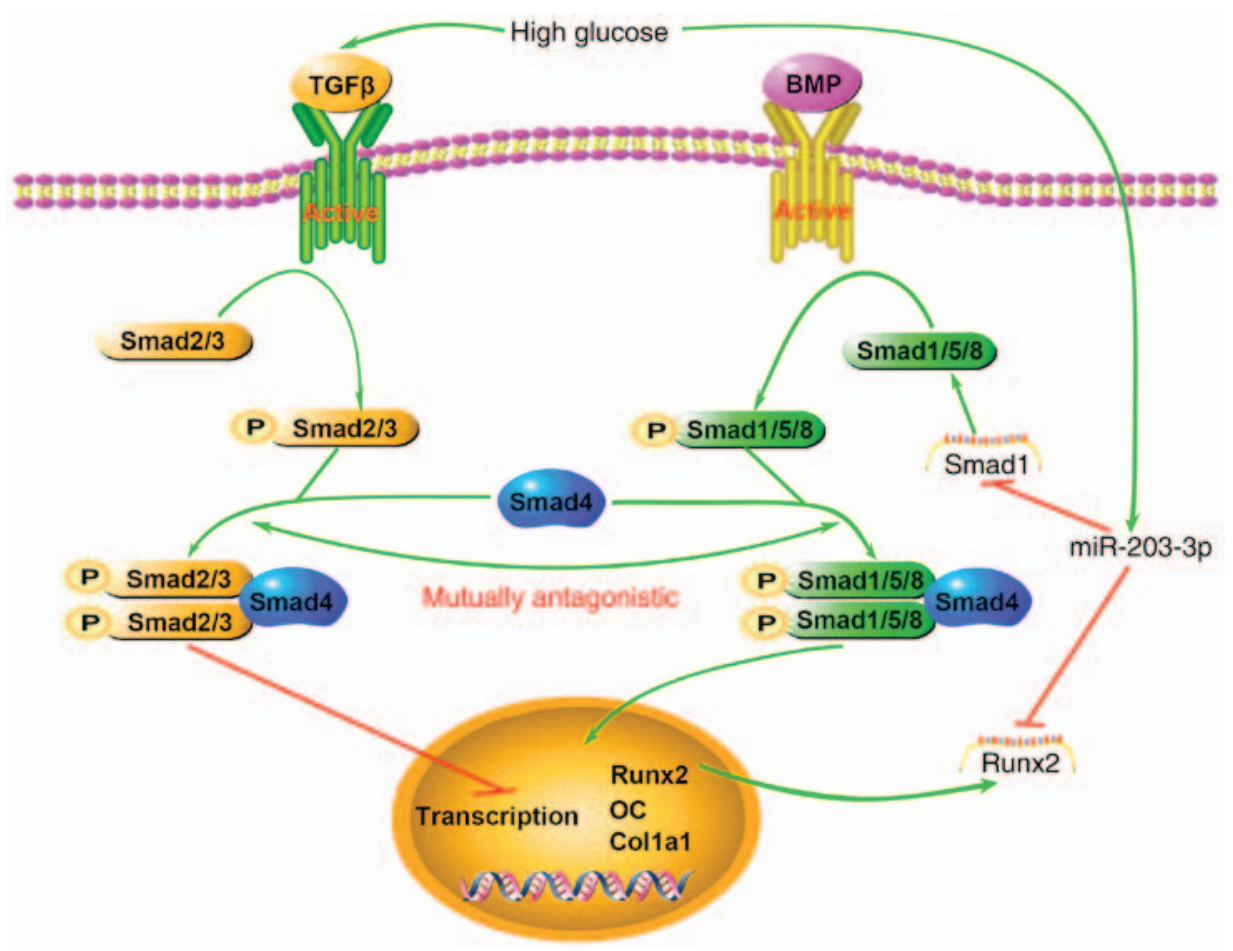

Figure 6. Schematic illustrating the association between high glucose, miR-203-3p and the BMP/Smad1 pathway. High glucose results in high expression of miR-203-3p, which represses osteogenesis by i) targeting Smad1 to directly attenuate the BMP/Smads pathway or promote the TGF- $\beta$ /activin pathway, which has an inhibitory role in osteoblast differentiation, by indirectly reducing Smad1 and Smad2/3 competition for Smad4 and the two pathways act synergistically; ii) targeting Runx2 to attenuate the synergistic effect on the BMP/Smads pathway or downregulating the downstream transcription of osteogenic genes. BMP, bone morphogenetic protein; TGF, transforming growth factor; miR, microRNA; Runx2, runt-related transcription factor 2; OC, osteocalcin; P, phosphate; Colla1, collagen type $1 \propto 1$.

Smad1 overexpression plasmid was co-transfected with agomir-203-3p or agomir-NC into C3H10T1/2 cells and overexpression of Smad1 protein was confirmed by western blot analysis (Fig. 5B). Ectopic expression of Smad1 appeared to attenuate the miR-203-3p-mediated suppression of osteogenic differentiation (Fig. 5C and D). These results indicated that miR-203-3p inhibited osteogenic differentiation, in part via the downregulation of Smadl expression.

\section{Discussion}

Diabetes mellitus is a metabolic disorder that affects bone metabolism in the entire body, which, in turn, inevitably affects the bone metabolism and bone mass in the jaw $(1,2)$. Unlike skeletal limbs, which originate from the mesoderm, the jaw is derived from the neural crest of the embryo. Jaw injury is repaired by BMSCs of neural crest origin, while limb injury is repaired by BMSCs derived from the mesoderm. Studies that examined BMSCs of the jaw and of the tibia demonstrated that BMSCs of different sources had different biological characteristics (4). To date, studies on the effects of diabetes on osteogenesis have mostly focused on skeletal limbs and cells cultured in vitro, while few studies have focused on the jaw bone (34-36). Therefore, to determine the potential tissue-specific factors that affect the stability of teeth and dental implants, DM-associated changes in jaw bones were assessed. In the present study, a rat model of T2DM was generated and the osteogenesis-associated gene expression in mandibles was assessed, revealing that osteogenesis was inhibited in the diabetic group, as were the cells cultured with high-glucose medium in vitro, which was consistent with the results of previous studies (34-36).

miRNAs may act as developmental regulators and modulate physiological and pathological processes by post-transcriptionally inhibiting gene expression (37). Previous studies have discovered that multiple miRNAs are involved in osteogenic differentiation. In the present study, it was hypothesized that certain miRNAs participate in inhibition of osteogenesis in diabetic jaw bones. To assess this, high-throughput small RNA sequencing was performed, which determined that the expression of a number of miRNAs in the mandibles of diabetic rats was different from that in the mandibles of normal rats, which was verified by RT-qPCR. Among them, the expression of certain miRNAs was consistent with the results obtained by screening BMSCs cultured under different glucose concentrations in vitro, including miR-181a-5p, miR-345-5p and miR-872-5p, while other miRNAs were not, including miR-149-5p, miR-185-5p and miR-674-3p (38). Therefore, there are differences between the in vivo and in vitro results, indicating that high-glucose culture may not completely simulate diabetic conditions, and better models need to be established. A literature review did not provide any studies that had performed miRNA screening of bone in diabetic conditions, not even of skeletal limbs. In the diabetic group, the present study revealed and upregulation of miR-203-3p, which has been reported to regulate the inflammatory response, inhibit the progression of several types of tumor and participate in the regulation of pathological processes of diabetes (39-43). It was identified that osteogenesis was repressed by overexpression of miR-203-3p and promoted when miR-203-3p was inhibited, which indicated that miR-203-3p 
participates in the repression of osteogenesis. In addition, to the best of our knowledge, the present study was the first to demonstrate that miR-203-3p suppresses osteogenesis.

To further study the mechanisms of osteogenesis repression by miR-203-3p, its target mRNAs were predicted with TargetScan, miRanda and Pictar, and the common results provided a pool of candidate genes. Among them, the predicted target site of Smad1 was evolutionarily conserved among vertebrates. The experimental results demonstrated that Smad1 expression was lower in the mandibles of diabetic rats as compared with that in the mandibles of normal rats. RT-qPCR and western blot analyses indicated that miR-203-3p markedly decreased Smad1 expression levels, while inhibition of miR-203-3p resulted in the upregulation of Smad1 at the mRNA and protein level, respectively. Using a miRNA target luciferase reporter assay, it was revealed that miR-203-3p overexpression decreased the luciferase activity of the reporter vector driven by the Smad1 3'-UTR, which indicated that miR-203-3p inhibits Smad1 expression by directly binding to its 3'-UTR and thereby degrading Smad1 mRNA or inhibiting its translation. To determine whether miR-203-3p modulates osteogenesis by repressing Smad1, cells were transfected with agomir-203-3p, resulting in attenuation of the protein expression of Smad1, as indicated by western blot analysis. Finally, repressed osteogenesis by miR-203-3p was attenuated by ectopic overexpression of Smad1, which indicated that miR-203-3p represses osteogenesis partially through downregulation of Smad1. The BMP/Smad1/5/8 pathway was demonstrated to be repressed by miR-203-3p.

Smad1 is an immediate downstream transducer mediating the BMP receptor in BMP signaling (44). Mice with osteoblast-specific Smad1 gene knockout displayed impaired postnatal bone formation (45). TGF- $\beta$ superfamily members have a variety of biological functions, as Smads may combine with a variety of transcription factor-targeting genes. Supra-physiological glucose and insulin levels of T2DM inhibit the maturation of primary human osteoblasts, and human immortalized BMSCs treated with sera from T2DM patients exhibited significantly increased TGF- $\beta$ signaling, while inhibition of this signaling effectively restored osteoblast maturation in the T2DM group (46). Smad proteins are classified into three subtypes: Receptor-regulated Smads (R-Smads), common-partner Smads (Co-Smads) and inhibitory Smads. Among them, Smad 2 and Smad3 serve as R-Smads transducing TGF- $\beta$ /activin-like signals, whereas Smad1, Smad5 and Smad8 act as R-Smads transducing BMP-like signals. R-Smads that are activated by BMP and Runx2 induce osteogenic differentiation. Smad4 is the only Co-Smad in mammals and is shared by the TGF- $\beta$ /activin and BMP pathways (47). TGF- $\beta$ has been described as the central factor in bone homeostasis, as it induces the recruitment and proliferation of osteoblasts (48), and several murine studies suggest that TGF- $\beta$ may also negatively influence the bone structure $(49,50)$. Smad1/5/8 and Smad2/3 compete for combination with Smad4 for signal transduction (51). In addition, miR-203-3p was reported to target Runx2 $(52,53)$, which, as a specific transcription factor, has an important role in the formation and reconstruction of bone tissue. Runx 2 interacts with Smads to enhance the expression of osteogenesis-specific genes (54). Using RT-qPCR, the present study demonstrated that miR-203-3p markedly decreased Smad1 mRNA expression, and western blot analysis indicated that miR-203-3p markedly decreased Smad1 protein expression, while the inhibition of miR-203-3p resulted in the upregulation of Smad1 mRNA and protein. It may therefore be hypothesized that high expression of miR-203-3p prevails in T2DM, which represses osteogenesis by targeting Smad1 to directly attenuate the BMP/Smads pathway or promote the TGF- $\beta$ /activin pathway, which has an inhibitory effect on osteoblast differentiation by reducing Smad1 and Smad2/3 competition for Smad4 indirectly, and these two pathways acting synergistically, as well as by targeting Runx 2 to attenuate the synergistic effect on the BMP/Smads pathways or downregulating the downstream transcription of osteogenic genes (Fig. 6). Of course, further experiments are necessary to verify these mechanisms.

In conclusion, the present study suggested that miR-203-3p has a role in the inhibition of osteogenesis in the jaw bones of diabetic rats, and overexpression of miR-203-3p in the jaw bones of diabetic rats or cells cultured in high-glucose medium inhibits osteogenesis by targeting Smad1, which is an important mediator of the BMP/Smad pathway. Therefore, the BMP/Smad pathway is attenuated, and the TGF- $\beta$ /activin pathway may be promoted through the reduction of Smad1. The present study provides a basis for gene therapy by inhibition of miR-203-3p in diabetic jaw bones, which may ameliorate diabetic osteoporosis and improve fracture healing, tooth stability and implant osseointegration.

\section{Acknowledgements}

The present study was supported by the Program for the Natural Science Foundation of China (grant no. 81470772), the Natural Science Foundation of Chongqing (grant nos. cstc2015jcyjA10028 and cstc2016jcyjA0238), the Medical Scientific Research Project of Chongqing (grant nos. 20141013 and 2015HBRC009), and the Program for Innovation Team Building at Institutions of Higher Education in Chongqing in 2016 and the Chongqing Municipal Key Laboratory of Oral Biomedical Engineering of Higher Education in 2014.

\section{Competing interests}

The authors declare that they have no competing interests.

\section{References}

1. Clementini M, Rossetti PH, Penarrocha D, Micarelli C, Bonachela WC and Canullo L: Systemic risk factors for peri-implant bone loss: A systematic review and meta-analysis. Int J Oral Maxillofac Surg 43: 323-334, 2014.

2. Nemtoi A, Ladunca O, Dragan E, Budacu C, Mihai C and Haba D: Quantitative and qualitative bone assessment of the posterior mandible in patients with diabetes mellitus: A cone beam computed tomography study. Rev Med Chir Soc Med Nat Iasi 117: 1002-1008, 2013.

3. de Morais JA, Trindade-Suedam IK, Pepato MT, Marcantonio E Jr, Wenzel A and Scaf G: Effect of diabetes mellitus and insulin therapy on bone density around osseointegrated dental implants: A digital subtraction radiography study in rats. Clin Oral Implants Res 20: 796-801, 2009.

4. Dobreva G, Chahrour M, Dautzenberg M, Chirivella L, Kanzler B, Fariñas I, Karsenty G and Grosschedl R: SATB2 is a multifunctional determinant of craniofacial patterning and osteoblast differentiation. Cell 125: 971-986, 2006. 
5. Liu Q and Paroo Z: Biochemical principles of small RNA pathways. Annu Rev Biochem 79: 295-319, 2010.

6. Ha M and Kim VN: Regulation of microRNA biogenesis. Nat Rev Mol Cell Biol 15: 509-524, 2014.

7. Zhang Y, Xie RL, Gordon J, LeBlanc K, Stein JL, Lian JB, van Wijnen AJ and Stein GS: Control of mesenchymal lineage progression by microRNAs targeting skeletal gene regulators Trps1 and Runx2. J Biol Chem 287: 21926-21935, 2012.

8. Li Z, Hassan MQ, Volinia S, van Wijnen AJ, Stein JL, Croce CM, Lian JB and Stein GS: A microRNA signature for a BMP2-induced osteoblast lineage commitment program. Proc Natl Acad Sci USA 105: 13906-13911, 2008.

9. Liu H, Sun Q, Wan C, Li L, Zhang L and Chen Z: MicroRNA-338-3p regulates osteogenic differentiation of mouse bone marrow stromal stem cells by targeting Runx 2 and Fgfr2. J Cell Physiol 229: 1494-1502, 2014.

10. Kim EJ, Kang IH, Lee JW, Jang WG and Koh JT: MiR-433 mediates ERR $\gamma$-suppressed osteoblast differentiation via direct targeting to Runx2 mRNA in C3H10T1/2 cells. Life Sci 92: 562-568, 2013.

11. Zuo B, Zhu J, Li J, Wang C, Zhao X, Cai G, Li Z, Peng J, Wang P, Shen C, et al: microRNA-103a functions as a mechanosensitive microRNA to inhibit bone formation through targeting Runx2. J Bone Miner Res 30: 330-345, 2015.

12. Tomé M, López-Romero P, Albo C, Sepúlveda JC, FernándezGutiérrez B, Dopazo A, Bernad A and González MA: miR-335 orchestrates cell proliferation, migration and differentiation in human mesenchymal stem cells. Cell Death Differ 18: 985-995, 2011.

13. Jia J, Tian Q, Ling S, Liu Y, Yang S and Shao Z: miR-145 suppresses osteogenic differentiation by targeting Sp7. FEBS Lett 587: 3027-3031, 2013.

14. Shi K, Lu J, Zhao Y, Wang L, Li J, Qi B, Li H and Ma C: MicroRNA-214 suppresses osteogenic differentiation of C2C12 myoblast cells by targeting Osterix. Bone 55: 487-494, 2013.

15. Baglìo SR, Devescovi V, Granchi D and Baldini N: MicroRNA expression profiling of human bone marrow mesenchymal stem cells during osteogenic differentiation reveals Osterix regulation by miR-31. Gene 527: 321-331, 2013.

16. Goettsch C, Rauner M, Pacyna N, Hempel U, Bornstein SR and Hofbauer LC: miR-125b regulates calcification of vascular smooth muscle cells. Am J Pathol 179: 1594-1600, 2011.

17. Chen S, Yang L, Jie Q, Lin YS, Meng GL, Fan JZ, Zhang JK, Fan J, Luo ZJ and Liu J: MicroRNA-125b suppresses the proliferation and osteogenic differentiation of human bone marrow-derived mesenchymal stem cells. Mol Med Rep 9: 1820-1826, 2014

18. Zhang JF, Fu WM, He ML, Wang $\mathrm{H}$, Wang WM, Yu SC, Bian XW, Zhou J, Lin MC, Lu G, et al: miR-637 maintains the balance between adipocytes and osteoblasts by directly targeting Osterix. Mol Biol Cell 22: 3955-3961, 2011.

19. Itoh T, Nozawa Y and Akao Y: MicroRNA-141 and -200a are involved in bone morphogenetic protein-2-induced mouse pre-osteoblast differentiation by targeting distal-less homeobox 5 . J Biol Chem 284: 19272-19279, 2009.

20. Xie Q, Wang Z, Bi X, Zhou H, Wang Y, Gu P and Fan X: Effects of miR-31 on the osteogenesis of human mesenchymal stem cells. Biochem Biophys Res Commun 446: 98-104, 2014.

21. Li J, Dong J, Zhang ZH, Zhang DC, You XY, Zhong Y, Chen MS and Liu SM: miR-10a restores human mesenchymal stem cell differentiation by repressing KLF4. J Cell Physiol 228 2324-2336, 2013

22. Li Z, Hassan MQ, Jafferji M, Aqeilan RI, Garzon R, Croce CM van Wijnen AJ, Stein JL, Stein GS and Lian JB: Biological functions of miR-29b contribute to positive regulation of osteoblast differentiation. J Biol Chem 284: 15676-15684, 2009.

23. Lin EA, Kong L, Bai XH, Luan Y and Liu CJ: miR-199a, a bone morphogenic protein 2-responsive MicroRNA, regulates chondrogenesis via direct targeting to Smad1. J Biol Chem 284: 11326-11335, 2009.

24. Kureel J, Dixit M, Tyagi AM, Mansoori MN, Srivastava K, Raghuvanshi A, Maurya R, Trivedi R, Goel A and Singh D: miR-542-3p suppresses osteoblast cell proliferation and differentiation, targets BMP-7 signaling and inhibits bone formation. Cell Death Dis 5: e1050, 2014.

25. Luzi E, Marini F, Sala SC, Tognarini I, Galli G and Brandi ML: Osteogenic differentiation of human adipose tissue-derived stem cells is modulated by the miR-26a targeting of the SMAD1 transcription factor. J Bone Miner Res 23: 287-295, 2008

26. Zheng L, Tu Q, Meng S, Zhang L, Yu L, Song J, Hu Y, Sui L, Zhang J, Dard M, et al: Runx2/DICER/miRNA pathway in regulating osteogenesis. J Cell Physiol 232: 182-191, 2017.
27. Ko JY, Chuang PC, Chen MW, Ke HC, Wu SL, Chang YH, Chen YS and Wang FS: MicroRNA-29a ameliorates glucocorticoid-induced suppression of osteoblast differentiation by regulating $\beta$-catenin acetylation. Bone 57: 468-475, 2013.

28. Wang T and Xu Z: miR-27 promotes osteoblast differentiation by modulating Wnt signaling. Biochem Biophys Res Commun 402 $186-189,2010$.

29. Hassan MQ, Maeda Y, Taipaleenmaki H, Zhang W, Jafferji M, Gordon JA, Li Z, Croce CM, van Wijnen AJ, Stein JL, et al: miR-218 directs a Wnt signaling circuit to promote differentiation of osteoblasts and osteomimicry of metastatic cancer cells. J Biol Chem 287: 42084-42092, 2012.

30. Clark EA, Kalomoiris S, Nolta JA and Fierro FA: Concise review: MicroRNA function in multipotent mesenchymal stromal cells. Stem cells 32: 1074-1082, 2014

31. Gaur T, Hussain S, Mudhasani R, Parulkar I, Colby JL, Frederick D, Kream BE, van Wijnen AJ, Stein JL, Stein GS, et al: Dicer inactivation in osteoprogenitor cells compromises fetal survival and bone formation, while excision in differentiated osteoblasts increases bone mass in the adult mouse. Dev Biol 340: 10-21, 2010

32. Schmittgen TD and Livak KJ: Analyzing real-time PCR data by the comparative C(T) method. Nat Protoc 3: 1101-1108, 2008

33. Lu H, Kraut D, Gerstenfeld LC and Graves DT: Diabetes interferes with the bone formation by affecting the expression of transcription factors that regulate osteoblast differentiation. Endocrinology 144: 346-352, 2003.

34. García-Hernández A, Arzate H, Gil-Chavarria I, Rojo R and Moreno-Fierros L: High glucose concentrations alter the biomineralization process in human osteoblastic cells. Bone 50 : 276-288, 2012

35. Ogawa N, Yamaguchi T, Yano S, Yamauchi M, Yamamoto M and Sugimoto T: The combination of high glucose and advanced glycation end-products (AGEs) inhibits the mineralization of osteoblastic MC3T3-E1 cells through glucose-induced increase in the receptor for AGEs. Horm Metab Res 39: 871-875, 2007.

36. Gopalakrishnan V, Vignesh RC, Arunakaran J, Aruldhas MM and Srinivasan N: Effects of glucose and its modulation by insulin and estradiol on BMSC differentiation into osteoblastic lineages. Biochem Cell Biol 84: 93-101, 2006.

37. van Rooij E: The art of microRNA research. Circ Res 108: 219-234, 2011.

38. Wang JC: miR-467f modulates osteogenic differentiation of mice bone mesenchymal stem cells in high glucose environment. Military Medical School, Beijing, 2013 (In Chinese).

39. Yang Z, Zhong L, Zhong S, Xian R and Yuan B: miR-203 protects microglia mediated brain injury by regulating inflammatory responses via feedback to MyD88 in ischemia. Mol Immunol 65: 293-301, 2015

40. Okumura T, Shimada Y, Moriyama M, Takei Y, Omura T, Sekine S, Nagata T, Shimizu K and Tsukada K: MicroRNA-203 inhibits the progression of esophageal squamous cell carcinoma with restored epithelial tissue architecture in vivo. Int J Oncol 44 1923-1932, 2014

41. Yu X, Jiang X, Li H, Guo L, Jiang W and Lu SH: miR-203 inhibits the proliferation and self-renewal of esophageal cancer stem-like cells by suppressing stem renewal factor Bmi-1. Stem Cells Dev 23: 576-585, 2014.

42. Delic D, Eisele C, Schmid R, Luippold G, Mayoux E and Grempler R: Characterization of Micro-RNA changes during the progression of type 2 diabetes in Zucker diabetic fatty rats. Int J Mol Sci 17: pii: E665, 2016.

43. Liu J, Xu Y, Shu B, Wang P, Tang J, Chen L, Qi S, Liu X and Xie J: Quantification of the differential expression levels of microRNA-203 in different degrees of diabetic foot. Int J Clin Exp Pathol 8: 13416-13420, 2015.

44. Hoodless PA, Haerry T, Abdollah S, Stapleton M, O'Connor MB, Attisano L and Wrana JL: MADR1, a MAD-related protein that functions in BMP2 signaling pathways. Cell 85: 489-500, 1996.

45. Wang M, Jin H, Tang D, Huang S, Zuscik MJ and Chen D: Smad1 plays an essential role in bone development and postnatal bone formation. Osteoarthritis Cartilage 19: 751-762, 2011.

46. Ehnert S, Freude T, Ihle C, Mayer L, Braun B, Graeser J, Flesch I, Stöckle U, Nussler AK and Pscherer S: Factors circulating in the blood of type 2 diabetes mellitus patients affect osteoblast maturation-description of a novel in vitro model. Exp Cell Res 332: 247-258, 2015

47. Miyazono K, Maeda S and Imamura T: Coordinate regulation of cell growth and differentiation by TGF-beta superfamily and Runx proteins. Oncogene 23: 4232-4237, 2004 
48. Pfeilschifter J, Bonewald L and Mundy GR: Characterization of the latent transforming growth factor beta complex in bone. J Bone Miner Res 5: 49-58, 1990.

49. Edwards JR, Nyman JS, Lwin ST, Moore MM, Esparza J, O'Quinn EC, Hart AJ, Biswas S, Patil CA, Lonning S, et al: Inhibition of TGF- $\beta$ signaling by 1 D11 antibody treatment increases bone mass and quality in vivo. J Bone Miner Res 25: 2419-2426, 2010.

50. Mohammad KS, Chen CG, Balooch G, Stebbins E, McKenna CR, Davis H, Niewolna M, Peng XH, Nguyen DH, Ionova-Martin SS et al: Pharmacologic inhibition of the TGF-beta type I receptor kinase has anabolic and anti-catabolic effects on bone. PLoS One 4: e5275, 2009.

51. Matsumoto Y,Otsuka F, Hino J,Miyoshi T, Takano M, Miyazato M, Makino $\mathrm{H}$ and Kangawa $\mathrm{K}$ : Bone morphogenetic protein-3b (BMP-3b) inhibits osteoblast differentiation via Smad2/3 pathway by counteracting Smad1/5/8 signaling. Mol Cell Endocrinol 350: $78-86,2012$.
52. Taipaleenmaki H, Browne G, Akech J, Zustin J, van Wijnen AJ, Stein JL, Hesse E, Stein GS and Lian JB: Targeting of Runx 2 by miR-135 and miR-203 impairs progression of breast cancer and metastatic bone disease. Cancer Res 75: 1433-1444, 2015.

53. Saini S, Majid S, Yamamura S, Tabatabai L, Suh SO, Shahryari V, Chen Y, Deng G, Tanaka Y and Dahiya R: Regulatory Role of mir-203 in prostate cancer progression and metastasis. Clin Cancer Res 17: 5287-5298, 2011.

54. Lee MH, Kwon TG, Park HS, Wozney JM and Ryoo HM: BMP-2-induced Osterix expression is mediated by Dlx 5 but is independent of Runx2. Biochem Biophys Res Commun 309: 689-694, 2003.

This work is licensed under a Creative Commons Attribution-NonCommercial-NoDerivatives 4.0 International (CC BY-NC-ND 4.0) License. 